\title{
Vacuum Diagnosis and Testing of a Dirty Thermal Vacuum Chamber
}

\author{
Taeil Chung,*, Jong Yeon Lim ${ }^{\mathrm{b}}$, Sangbaek Kang, Yongho Yoo ${ }^{\mathrm{a}}$, and Hyu-Soung Shin ${ }^{\mathrm{a}}$ \\ ${ }^{a}$ Department of Future Technology and Convergence Research, Korea Institute of Civil Engineering and Building Technology, \\ Gyeonggi-do 10223, Republic of Korea \\ ${ }^{b}$ Semiconductor Integrated Metrology Team, Korea Research Institute of Standards and Science, Daejeon, 34113, Republic of Korea \\ ${ }^{c} R \& D$ Center, VACSCO CO., LTD., Chungcheongbuk-do 28185, Republic of Korea
}

Received September 27, 2018; revised October 25, 2018; accepted October 29, 2018

\begin{abstract}
The Korea Institute of Civil Engineering and Building Technology is currently developing a planetary surface environment simulator for the Moon and Mars. Known as a dirty thermal vacuum chamber (DTVC), this simulator contains a large volume of soil that undergoes extensive testing using special equipment. The construction of the DTVC started in 2017 and is expected to be completed by the end of 2019. The DTVC is a large vacuum chamber with an inner space measuring $4.70 \mathrm{~m}(\mathrm{~W}) \times 4.70 \mathrm{~m}(\mathrm{H}) \times 4.65 \mathrm{~m}(\mathrm{~L})$. The goal of the first construction stage was to achieve a target pressure of $5 \times 10^{-8}$ mbar without soil. After assembling the chamber body and the pumping system, we attempted to reduce the leakage with the help of pressure buildup analysis, helium leak testing, and residual gas analysis. After vacuum diagnosis of the chamber, the overall leakage decreased and the target pressure was achieved in approximately 93 hours after the pumping commenced.
\end{abstract}

Keywords: Dirty thermal vacuum chamber, Vacuum diagnosis, Leak detection, Pressure buildup, Residual gas analysis, Helium leak detection

\section{Introduction}

The Korea Institute of Civil Engineering and Building Technology is in the process of constructing a large-scale planetary surface environment simulator that can simulate the pressure, temperature, and regolith conditions of the Moon and Mars [1]. We refer to this simulator as a dirty thermal vacuum chamber (DTVC). The DTVC is a thermal vacuum chamber that contains a large amount of soil. The main processing chamber was manufactured at the end of 2017 (as displayed in Fig. 1.). The thermal shrouds and liquid nitrogen $\left(\mathrm{LN}_{2}\right)$ supply system will be added to the main chamber in 2019 to produce a cryogenic environment. After construction of the main chamber, we analyzed the vacuum properties of the main chamber and conducted a vacuum test to achieve the target pressure.

Leaks within a vacuum system need to be minimized to achieve a high vacuum level. Leaks may appear due to various defects within the construction materials and/or between permanent or flanged joints. Several methods are available to find leaks within a chamber [2]. For example, large leaks can be detected based on mechanical effects with the use of an ultrasonic detector or soapy water, while

*Corresponding author

E-mail: taeilchung@kict.re.kr pressure buildup (pressure rise) tests and tracer gas detectors are used for the detection of smaller leaks [3]. Typically, when looking for leaks, a simple mechanical method is employed first to identify manufacturing errors or large leaks, followed by more sophisticated leak detection methods, once those major leaks have been addressed, to find and plug small leaks.

The fabrication of vacuum containers and the investigation of methods for leak detection have been widely studied, but large vacuum containers with a volume above $100 \mathrm{~m}^{3}$ and more than 50 flanged ports remain uncommon. The target pressure of the DTVC without soil is $5 \times 10^{-8} \mathrm{mbar}$, and leakage management of the multiple

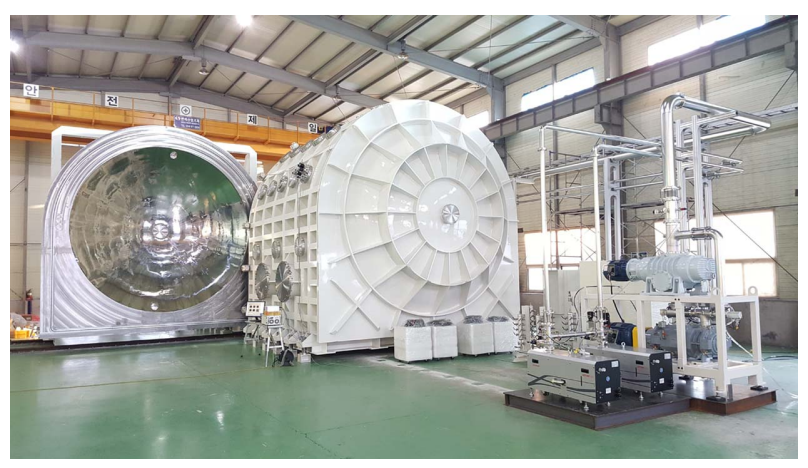

Figure 1. The first stage of DTVC construction. 
connections is required to achieve this target. Herein, the integrity of the main processing chamber, which was completed as the first stage of DTVC construction, was investigated with the help of pressure buildup analysis, helium leak testing, and residual gas analysis. An analysis of the experimental data for the various leak detection methods and the results of the final vacuum test are also presented.

\section{Experimental details}

The goal of the first stage of DTVC construction was to fabricate the main processing chamber. The DTVC is in the form of a mailbox with inner dimensions of $4.70 \mathrm{~m}$ $(\mathrm{W}) \times 4.70 \mathrm{~m}(\mathrm{H}) \times 4.65 \mathrm{~m} \quad(\mathrm{~L})$. The vacuum exhaust system of the DTVC consists of a dry screw vacuum pump, a booster pump, two turbo molecular pumps (TMPs), and two cryogenic pumps (CPs). Figure 2 and Table I present a schematic of the vacuum system and the specifications of the first stage of the DTVC construction, respectively.

To achieve high vacuum levels, leaks in the chamber need to be minimized. The gas flow balance equation of the system can be modeled as:

$$
V \frac{d P}{d t}=q_{\text {outgassing }}+q_{\text {leak }}-P \cdot S
$$

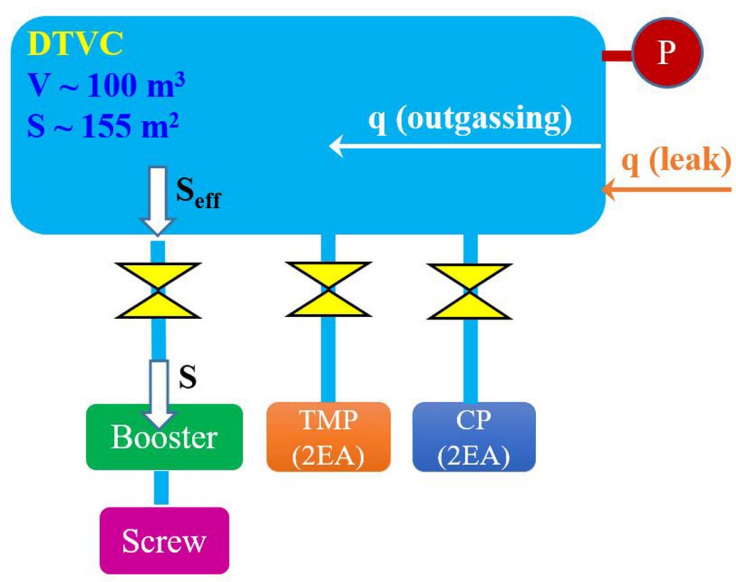

Figure 2. Schematic diagram of the vacuum system.

Table I. Specification of the DTVC.

\begin{tabular}{|c|c|}
\hline $\begin{array}{c}\text { Inner } \\
\text { Dimension }\end{array}$ & $4.70 \mathrm{~m}(\mathrm{~W}) \times 4.70 \mathrm{~m}(\mathrm{H}) \times 4.65 \mathrm{~m}(\mathrm{D})$ \\
\hline Inner Volume & $100 \mathrm{~m}^{3}$ \\
\hline Pressure & $\begin{array}{l}<5 \times 10-8 \mathrm{mbar} \text { (without soil) } \\
<1 \times 10-4 \mathrm{mbar}(\text { with soil) }\end{array}$ \\
\hline Material & 304 Stainless Steel \\
\hline $\begin{array}{l}\text { Vacuum } \\
\text { Exhaust } \\
\text { System }\end{array}$ & $\begin{array}{l}\text { Dry screw vacuum pump and booster pump: } \\
4800 \mathrm{~m}^{3} / \mathrm{h}(1333 \mathrm{~L} / \mathrm{s}) \\
\text { TMP }(2 \mathrm{EA}): 2,100 \mathrm{~L} / \mathrm{s}\left(\mathrm{N}_{2}\right), 1,900 \mathrm{~L} / \mathrm{s}(\mathrm{Ar}), \\
2,050 \mathrm{~L} / \mathrm{s}(\mathrm{He}), 1,750 \mathrm{~L} / \mathrm{s}\left(\mathrm{H}_{2}\right) \\
\mathrm{CP}(2 \mathrm{EA}): 26,000 \mathrm{~L} / \mathrm{s}\left(\mathrm{N}_{2}\right), 73,450 \mathrm{~L} / \mathrm{s}\left(\mathrm{H}_{2} \mathrm{O}\right), \\
20,000 \mathrm{~L} / \mathrm{s}(\mathrm{Ar}), 44,000 \mathrm{~L} / \mathrm{s}(\mathrm{H} 2)\end{array}$ \\
\hline
\end{tabular}

where $V$ is the volume of the chamber, $P$ is the pressure of the chamber, $q_{\text {outgassing }}$ is the outgassing rate of the chamber, $q_{\text {leak }}$ is the leak rate of the chamber, and $S$ is the pumping speed. Considering the target pressure as the ultimate pressure $\left(\mathrm{P}=5 \times 10^{-8}, \frac{d P}{d t}=0\right)$ and the $\mathrm{N}_{2}$ pumping speed of the CPs and TMPs, the allowable total gas load $\left(q_{\text {total }}\right)$ can be calculated using Eq. (1):

$$
\begin{aligned}
q_{\text {total }} & =q_{\text {outgassing }}+q_{\text {leak }}=P \cdot S \\
=\left(5 \times 10^{-8} \mathrm{mbar}\right) & \cdot(2,100 \mathrm{~L} / \mathrm{s}+26,000 \mathrm{~L} / \mathrm{s}) \cdot(2 E A) \\
& \cong 3 \times 10^{-3} \mathrm{mbar} \cdot \mathrm{L} / \mathrm{s} .
\end{aligned}
$$

From the calculation of Eq. (2), it is determined that the total gas load of the chamber should be less than $3 \times 10^{-3}$ $\mathrm{mbar} \cdot \mathrm{L} / \mathrm{s}$ to achieve the target pressure.

We decided to check the integrity of the chamber using pressure buildup analysis. This method provides sufficient information to diagnose the state of the chamber by measuring the leaks and outgassing using only pressure gauges and no other special equipment.

For the pressure buildup test, we evacuated the chamber to a pressure of $2 \times 10^{-6}$ mbar using a dry-compressing screw vacuum pump with a booster pump and two TMPs. The valve was then closed to isolate the pumps from the chamber and the increase in pressure was measured.

Considering Eq. (1) and $\mathrm{S}=0$, the total gas load can be given by Eq. (3):

$$
q_{\text {total }}=q_{\text {outgassing }}+q_{\text {leak }}=V \frac{d P}{d t}
$$

If we assume that the outgassing is dominant in the total gas load, Eq. (3) can be expressed as:

$$
V \frac{d P}{d t} \cong q_{\text {outgassing }}=q_{0} t^{-n}-P \cdot S_{r e-a d}
$$

where $S_{r e-a d}$ is the pumping speed due to the effect of reabsorption of outgassing, $q_{0}$ is the initial outgassing rate, and $n$ is constant.

If we assume that a leak is dominant in the total gas load, Eq. (3) can be expressed as:

$$
V \frac{d P}{d t} \cong q_{\text {leak }}
$$

In the pressure buildup test, if the outgassing is dominant in the total gas load, the rates of outgassing and reabsorption become similar over time and the pressure rise curve gradually converges. On the other hand, if a leak is dominant in the total gas load, the pressure rise curve increases almost linearly, as observed in Fig. 3.

We measured the pressure rise of the chamber over 110 hours, and the average gas load was $3 \times 10^{-3} \mathrm{mbar} \cdot \mathrm{L} / \mathrm{s}$ (Fig. 4). Although this is similar to the allowable total gas load to achieve the target pressure, it was decided that a leak is dominant in the total gas load as the pressure rise 


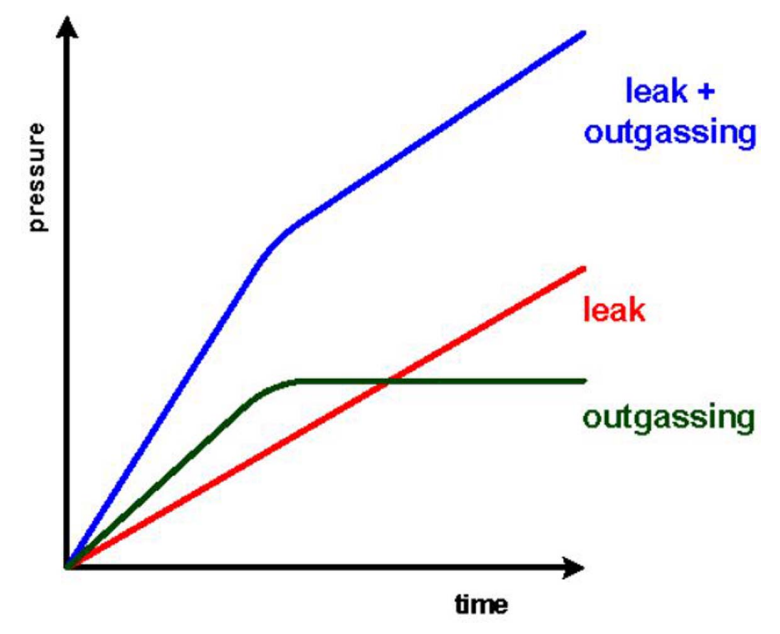

Figure 3. Pressure increase due to outgassing and leaks [3].

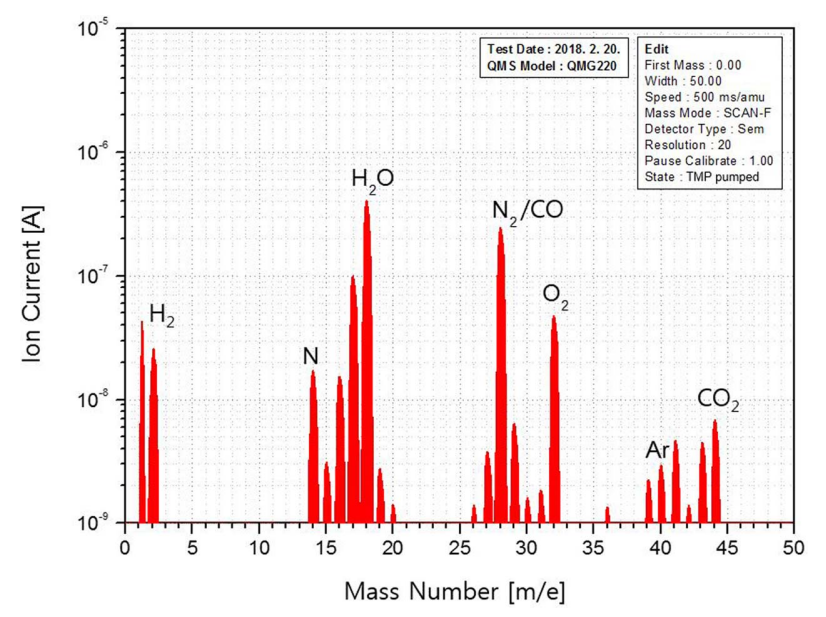

Figure 5. The result of residual gas analysis during TMP operation.

curve increased linearly over a long period of time. We also analyzed residual gases in the chamber before the pressure buildup test. Figure 5 presents the results of this analysis during the TMP operation; the proportions of $\mathrm{N}$, $\mathrm{N}_{2}, \mathrm{O}_{2}, \mathrm{Ar}$, and $\mathrm{CO}_{2}$ were relatively high. From these results, it can be concluded that there were significant leaks in the chamber [4].
Based on the results of the pressure buildup test and residual gas analysis, we concluded that the leakage in the main processing chamber was high and a precision leak testing was required to achieve the target pressure for a reasonable period of time.

Although the total gas load from the pressure buildup testing almost met the maximum total gas load required to achieve the target pressure, a leak is dominant in the gas load, and the results of the residual gas analysis indicated that the chamber had a considerable leakage problem. Therefore, we decided to proceed with a precision leak testing using a helium leak detector. Various methods to use a helium leak detector in large vacuum vessels have been proposed [2,5]. We sealed welding lines and flanges using vinyl hoods and tape. Helium was admitted to each enveloped part locally, and the leak rate of the joints was verified. Figure 6 presents how the welding lines and flanges were prepared for the helium leak test, and Fig. 7 displays photographs of the sealing. The helium detector was connected to the middle of the TMP's foreline (Fig. 8).

The main chamber was evacuated to approximately $10^{-6}$ mbar for the helium leak test. The pressure at the joint of the helium detector's connection line and the TMP's foreline was approximately $10^{-3} \mathrm{mbar}$. As the pumping speed of the chamber's TMP forepump $(83.3 \mathrm{~L} / \mathrm{s})$ was greater than the helium detector's forepump $(0.5 \mathrm{~L} / \mathrm{s})$, a significant volume of helium in the chamber flowed not only to the helium detector but also to the TMP's forepump. Therefore, the actual leak rate of the examined components was higher than the leak rate measured by the detector. The effective pumping speed of the TMP's forepump and the helium detector need to be considered to calculate the specific helium distribution rate. Considering the molecular flow at the joint, we can calculate the conductance of each vacuum line [6]:

$$
\begin{gathered}
C=(12.1) \cdot \frac{d^{3}}{l}[L / s] \\
\frac{1}{S_{e f f}}=\frac{1}{C}+\frac{1}{S}
\end{gathered}
$$

\section{Pressure Build-up}

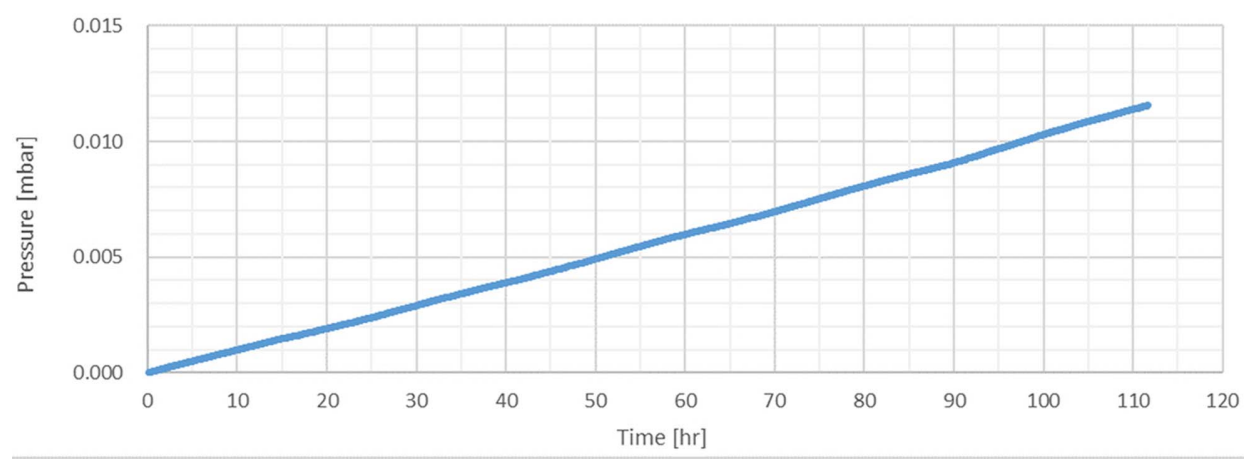

Figure 4. The result of a pressure buildup testing. 


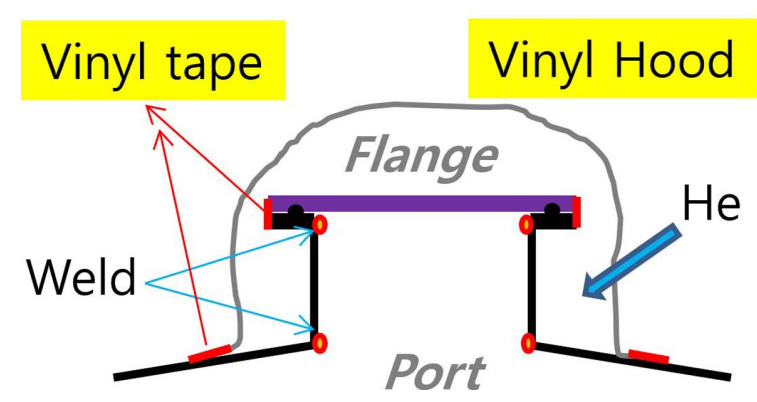

Figure 6. Method for sealing of flange gap and welding line.

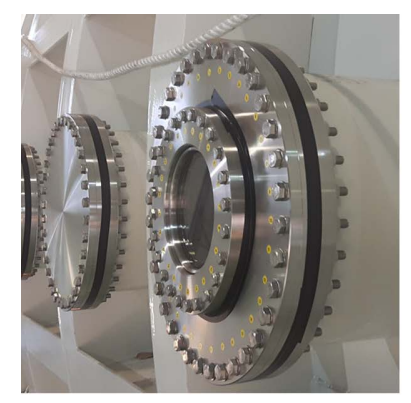

(a)

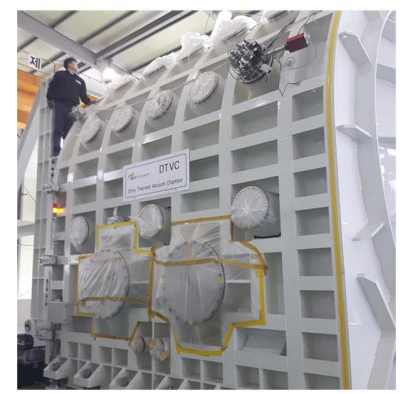

(c)

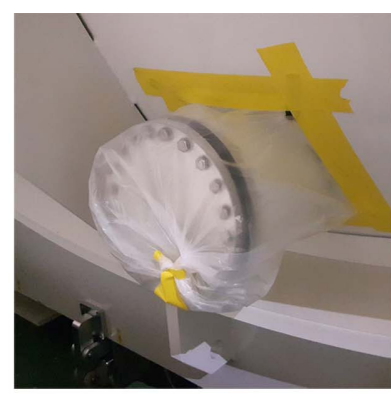

(b)

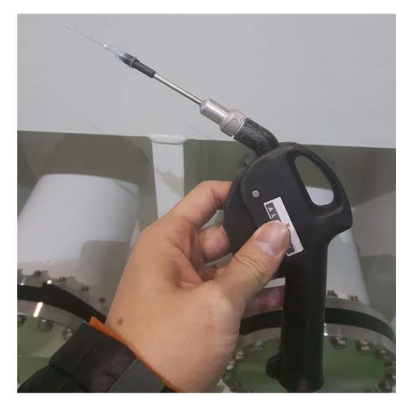

(d)
Figure 7. (a), (b), (c) actual photographs of the sealing for a helium leak test (d) a helium injection device with needle.

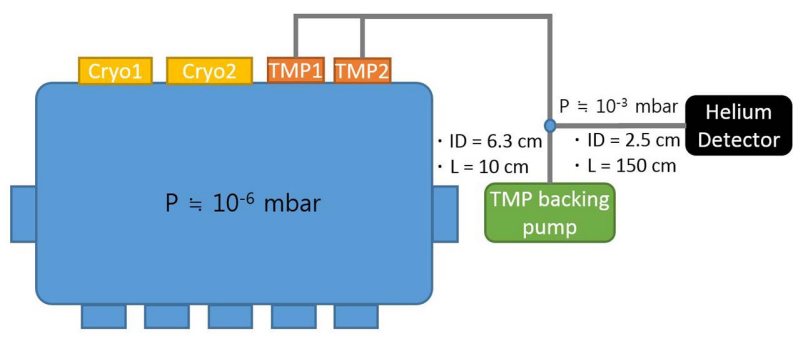

Figure 8. Install of a helium leak detector.

where $\mathrm{C}$ is the conductance of the pipe $(\mathrm{L} / \mathrm{s}), \mathrm{d}$ is the inner diameter of the pipe $(\mathrm{cm}), l$ is the length of the pipe (cm), $S$ is the pumping speed (L/s), and $S_{e f f}$ is the effective pumping speed $(\mathrm{L} / \mathrm{s})$.

Using the information shown in Fig. 8, the conductance of the vacuum line, the effective pumping speed, and the ratio of the helium distribution rate of the TMP's forepump and the helium detector can be calculated:

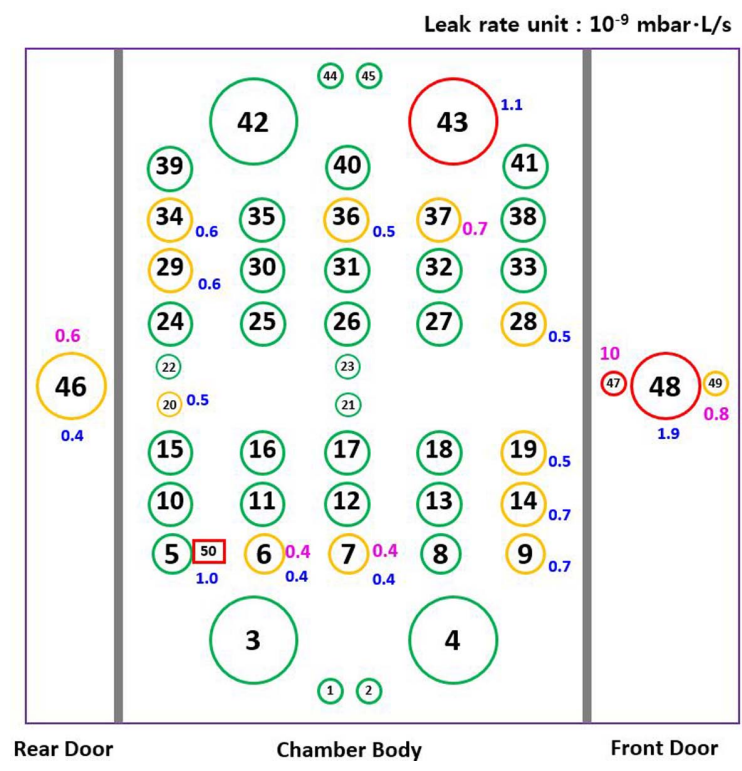

Figure 9. The result of helium leak testing.

$$
\begin{gathered}
C_{\text {forepump }}=(12.1) \cdot \frac{d^{3}}{l}(12.1) \cdot \frac{(6.3)}{(10)} \cong 303[\mathrm{~L} / \mathrm{s}] \\
C_{\text {detector }}=(12.1) \cdot \frac{d^{3}}{\frac{l}{l}(12.1) \cdot \frac{(2.5)}{(150)} \cong 1.26[\mathrm{~L} / \mathrm{s}]} \\
\left.S_{\text {eff_forepump }}=1 / \frac{1}{C_{\text {forepump }}}+\frac{S_{\text {forepump }}}{S_{\text {for }}}\right)= \\
1 /\left(\frac{1}{303}+\frac{1}{83.3}\right) \cong 65.4[\mathrm{~L} / \mathrm{s}] \\
S_{\text {eff_detector }}=1 /\left(\frac{1}{C_{\text {detector }}}+\frac{1}{S_{\text {detector }}}\right)= \\
1 /\left(\frac{1}{1.26}+\frac{1}{0.5}\right) \cong 0.358[L / s] \\
S_{\text {eff_forepump }}: S_{\text {eff_detector }}=65.4: 0.358 \cong 200: 1
\end{gathered}
$$

Based on these calculations, the actual leak rate can be estimated by multiplying 200 with the measured value. If the pumping speed of a helium detector's forepump is enough to operate the main chamber's TMP, we can connect a helium detector serially to the foreline without the main chamber's TMP forepump, and measure the leak rate directly without considering the helium distribution for the TMP forepump.

We first checked the flanges in the chamber. All the flanges were sealed with copper gaskets. The flange gap was enveloped with vinyl tape and helium was injected using a needle. After assessing the flange gaps, the welding lines between the chamber and ports were enveloped with a vinyl hood, and helium was injected into the vinyl hood. Figure 9 presents the results of the helium leak testing. A total of 50 flanges and 50 welding lines were checked, with the numbers in blue indicating the leak rate in between the flanges and those in purple indicating the leak rate in the welding lines between the chamber and ports detected by the helium detector. The measurement unit of the leak detector is $10^{-9} \mathrm{mbar} \cdot \mathrm{L} / \mathrm{s}$. When the helium detector recorded a value higher than $0.5 \times 10^{-9} \mathrm{mbar} \cdot \mathrm{L} / \mathrm{s}$, we 


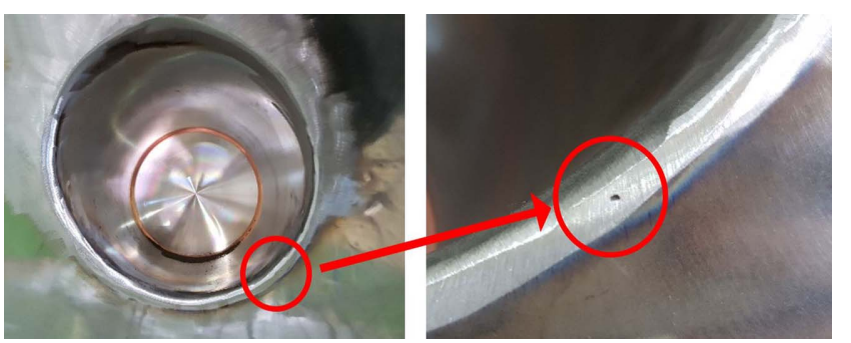

Figure 10. Defect of the weld in port \#47.

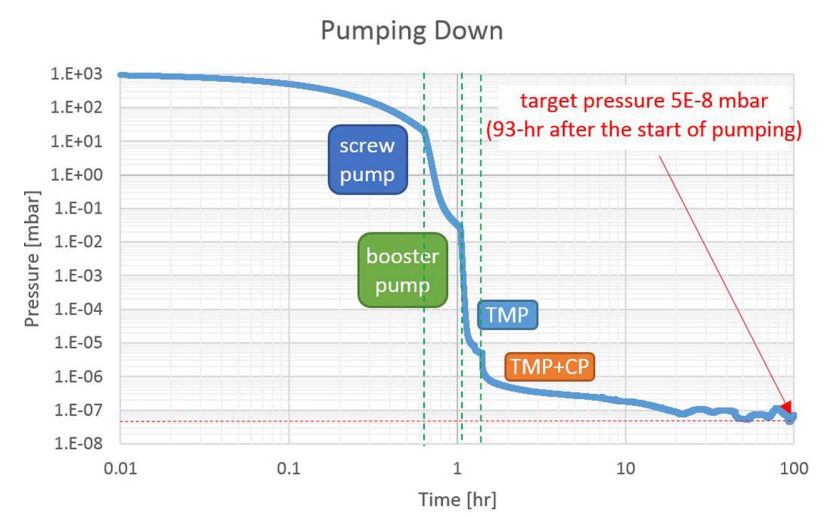

Figure 11. Pumping down curve of the DTVC.

checked its fastening state of flanges and adjusted the number to be $0.5 \times 10^{-9} \mathrm{mbar} \cdot \mathrm{L} / \mathrm{s}$ or less. The welding lines between the chamber and ports were also checked, and port \#47, which had the highest leak rate, was rewelded after removing the existing weld bead with a grinder (Fig. 10).

Considering the 200:1 helium distribution ratio and 100 joints, the leak rate can be estimated as:

$$
\begin{aligned}
q_{\text {leak }} \cong(\text { leak rate of a joint }) \times(\text { helium distribution ratio }) \\
\begin{aligned}
\text { (number of joints }) & =\left(0.5 \times 10^{-9} \mathrm{mbar} \cdot \mathrm{L} / \mathrm{s}\right) \times(200) \times(100) \\
& =1 \times 10^{-5} \mathrm{mbar} \cdot \mathrm{L} / \mathrm{s}
\end{aligned}
\end{aligned}
$$

The estimated leak rate of $1 \times 10^{-5} \mathrm{mbar} \cdot \mathrm{L} / \mathrm{s}$ becomes more suitable for a large vacuum container.

\section{Results and discussion}

A final vacuum test was conducted after the helium leak testing. The target pressure of $5 \times 10^{-8} \mathrm{mbar}$ was achieved in approximately 93 hours after the start of pumping (Fig. 11). It can be seen that the pumping down curve went up and down once $1 \times 10^{-7}$ mbar had been reached as the chamber was not tested at a constant temperature or humidity. Although the temperature at the testing location was not measured, the temperature data near the testing location was taken from the Korea Meteorological Administration and this data is comparable with the pressure data (Fig. 12). From Fig. 12, we estimated that the pressure in the chamber had been affected by the ambient

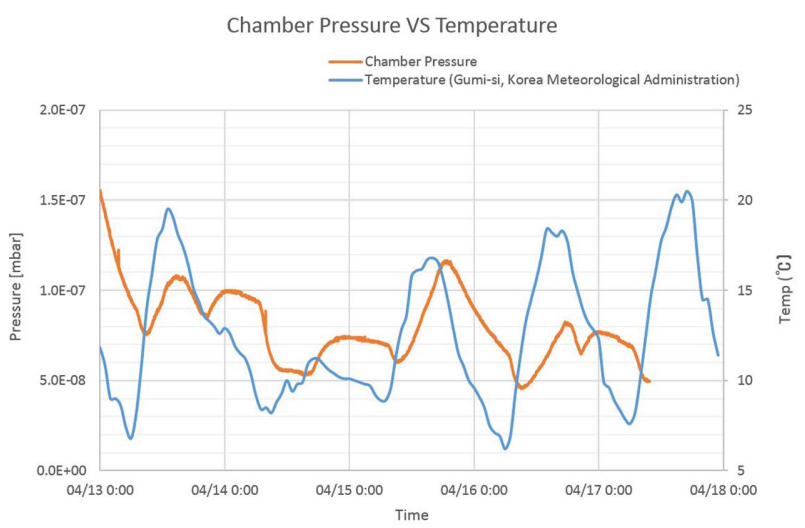

Figure 12. Comparison of temperature and pressure data.

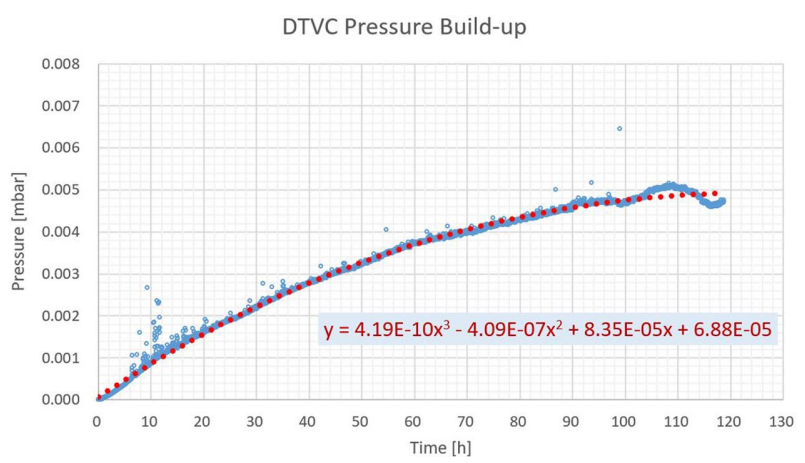

Figure 13. Pressure buildup analysis after helium leak testing.

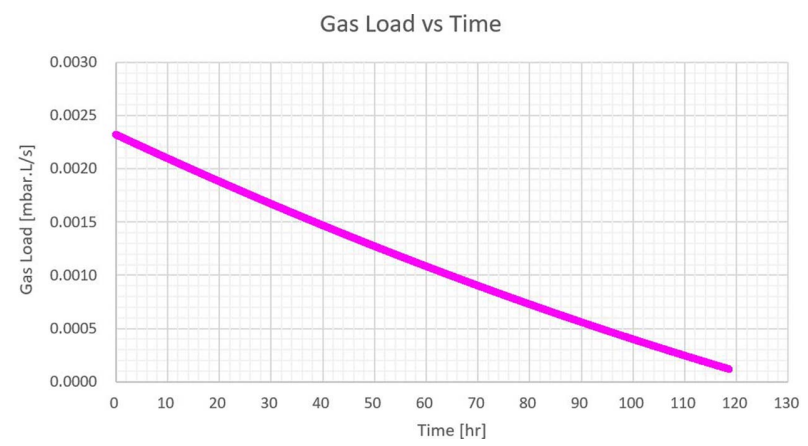

Figure 14. Gas load of the DTVC.

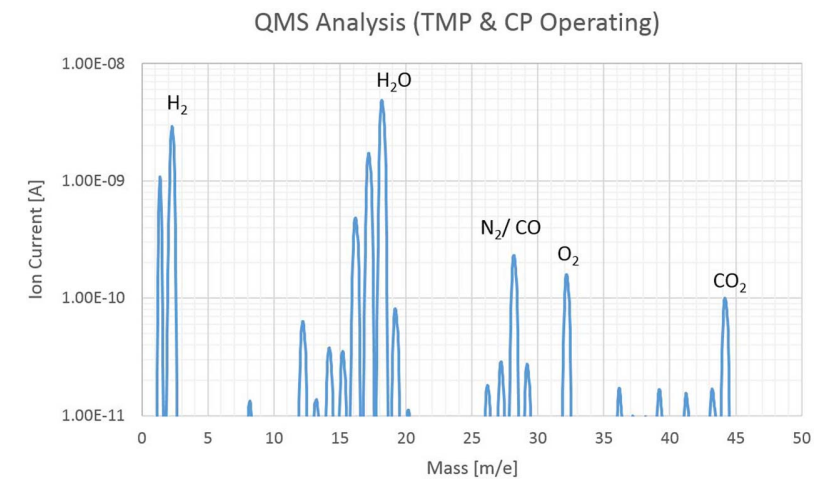

Figure 15. The result of residual gas analysis when the final vacuum testing.

temperature.

A pressure buildup test was conducted again after the helium leak detection test (Fig. 13). The slope of the 
pressure rise curve gradually decreased over time. The total gas load from the fitting curve in Fig. 13 is presented in Fig. 14. The total gas load gradually decreased from $2.32 \times 10^{-3} \mathrm{mbar} \cdot \mathrm{L} / \mathrm{s}$ to $1.14 \times 10^{-4} \mathrm{mbar} \cdot \mathrm{L} / \mathrm{s}$ in 120 hours. This indicates that a leak has been reduced to a level similar to the outgassing. Residual gas analysis was also performed (Fig. 15). Compared with Fig. 5, the ratio of $\mathrm{N}_{2}$ and $\mathrm{O}_{2}$ decreased, indicating that an air leak in the chamber had decreased.

\section{Conclusions}

Herein, the main chamber of the DTVC was investigated for leaks and vacuum testing was performed. We calculated the allowable total gas load required to achieve the target pressure and diagnosed the chamber through pressure buildup and residual gas analysis. It was observed that it is necessary to reduce a leak of the fabricated chamber. The connections of the flanges and welding lines between the chamber and the ports were checked using a helium leak detector. The leak rate of these components was measured and large leaks were subsequently fixed. The leak rate of the chamber was thus significantly reduced and the target pressure for the DTVC $\left(5 \times 10^{-8} \mathrm{mbar}\right)$ was achieved. A pressure buildup testing and residual gas analysis were conducted again, confirming that the integrity of the chamber had significantly improved. Future baking and cleaning operations inside the chamber will reduce the time required to reach the target pressure.

\section{Acknowledgments}

The authors would like to extend special thanks to the late Dr. S. R. In for his significant contribution to the design, experimentation, and analysis of this paper.

This research was supported by the research project "Development of an environmental simulator and advanced construction technologies over TRL 6 in extreme conditions," funded by the KICT.

\section{References}

[1] Y. Yoo, T. Chung, H. S. Shin, S. Kang, J. K. You, W. S. Choi, S. J. Nam, J. Y. Lim, and S. R. In, $54^{\text {th }}$ Winter Annual Conference of the Korean Vacuum Society (Heongsung, Korea, Feb. 7-9, 2018), pp. 103.

[2] H. Rottländer, W. Umrath, and G. Voss, Fundamentals of Leak Detection (Leybold GmbH, 2016), pp.4-30.

[3] K. Zapfe, Proceedings of the CERN Accelerator School: Vacuum in Accelerators, 16, pp. 227-240 (2016)

[4] Pfeiffer Vacuum GmbH, The Vacuum Technology Book, 2 (2), Asslar, 2013), pp.118-125.

[5] S. R. In, J. Korean Vacuum Soc. 16, 235 (2007)

[6] W. Umrath, Fundamentals of Vacuum Technology (Oerlikon, Leybold Vacuum GmbH, 2016), pp.9-18. 